\title{
BALLISTIC PERFORMANCE OF A QUENCHED AND TEMPERED STEEL AGAINST 7.62MM CALIBRE PROJECTILE
}

\author{
0. M. Sanusi ${ }^{1}$ and J. 0. Akindapo ${ }^{2}$ \\ 1 RESEARCH AND DEVELOPMENT CENTRE, DEFENCE INDUSTRIES CORPORATION OF NIGERIA, NIGERIA \\ 2 DePartment of Mechanical EngineERING, Nigerian DEFEnSE ACADEMy, Kaduna, NIGERIA \\ E-mail addresses: ${ }^{1}$ sanuthwale@gmail.com , ${ }^{2}$ jacobakindapo@gmail.com
}

\begin{abstract}
In this research effort, ballistic performance of a quenched and tempered steel was investigated. Low alloy steel was selected where austenization, quenching and finally tempering at $600{ }^{\circ} \mathrm{C}$ were applied to it. Thereafter, the heat-treated steel was shot with armour piercing $7.62 \mathrm{~mm}$ calibre and the occurrence of failure, after the interaction between the projectile and the steel, was investigated. The shot was performed at zero degree ( $0^{\circ}$ ) obliquity with a projectile velocity of $830 \mathrm{~m} / \mathrm{s}$. After the shot, microstructural and fractographical examinations were carried out on the sample taken from the perforated region using scanning electron microscopes to determine the matrix phase and secondary phases. It was observed that the steels had tempered martensitic-bainitic matrices after heat treatments; a crater was formed on the front side of the steel; deformed and transformed adiabatic shear bands had an effect on the crack formation and propagation in the matrix; and perforation mode of the steels was typical petalling.
\end{abstract}

Keywords: Projectile, petalling, ballistic impact, perforation, quenched \& tempered steel

\section{INTRODUCTION}

Metal and its alloys, ceramics, polymers and composite materials can be used as armour materials in structural protection technology. The conceptions such as hardness, strength and toughness are the main features for the ballistic performance of a given material. Recently, defence industry has been trying to find out materials having excellent ballistic performance under any defined threat and all attempts focus on the design of new alloys/materials, single or multi composite systems, processing techniques and secondary treatments. For this purpose, the search and development studies on blast and penetration-resistant materials (BPRMs) are very popular in many disciplines [1-3].

Many metals make great BPRMs and the most common ones include steels (ferrous alloys), aluminium and titanium alloys. The two purposes of metals in structural protection are stated as follows: protection against fragments and maintaining structural integrity. Metals are highly useful in protecting structures against explosions because of their inherent strength, toughness and energy absorption capability $[1,3]$. The most known alloy as protection material is the armour steel. The only armour grade steel, which is currently used for structural applications, is the rolled homogenous armour (RHA) [1, 4]. Armour steel should have properties which include: high resistance to perforation and ballistic impacts; easy fabricability; adequate fatigue and wear resistance under service conditions.

Hardness is an important feature for the materials used for armour strategy [1-3]. Sangoy and others.[5]reported that high hardness of given armour steel directly determines the ballistic performance and perforation mode. Many studies on the ballistic impact behaviour of the steels revealed that relationship exists between hardness of the steel matrix and ballistic performance of the steel after dynamic impact. In addition, toughness is another critical property for a given armour material under a dynamic attack of projectiles having high kinetic energies. It is generally considered that armour steels 
having high toughness will be very useful to resist ballistic impacts without being fractured. As it is well known, alloying and also heat treatments affect the toughness of the materials [2, 5 - 7].

This research was initiated in order to harness the potentials of Nigeria's commercially available steel in developing armour plates via application of heat treatments consisting of austenisation, quenching and tempering. These heat treatment processes are observed on the frequently imported armour steel.Thereafter, the research studied the performance of the treated plate against armour piercing $7.62 \mathrm{~mm}$ calibre and the occurrence of failure in order to evaluate its feasibility in ballistic applications.

\section{EXPERIMENTAL PROCEDURE}

\subsection{Materials and Methods}

Table 1 shows the chemical composition of the commercial $10 \mathrm{~mm}$ thick steel plate used in this study. $300 \times 1000 \mathrm{~mm}$ plate was prepared from the sheet for the ballistic test while the steel has an original alloy design to develop a new armour steel according to MIL-DTL-46100D/E [8-9].

Table 2 shows the heat treatment conditions applied on the experimental steel at the Heat and Surface Treatment Factory, Defence Industries Corporation of Nigerian (DICON), Kaduna. As it may be seen, the heat treatment (thermo-mechanical process) consists of austenization, quenching, and finally tempering in accordance with the MIL-DTL-46100D/E standards and with conventional armour steels [8-11].

All mechanical properties are represented in Table 3. It should be noted that Notched impact test was carried out at a temperature of $-20^{\circ} \mathrm{C}$.

Table 1: The chemical composition (Wt-\%) of the experimental steel

\begin{tabular}{cc}
\hline Metal & \% composition \\
\hline $\mathrm{C}$ & 0.24 \\
$\mathrm{Mn}$ & 0.19 \\
$\mathrm{Si}$ & 0.18 \\
$\mathrm{Ni}$ & 0.04 \\
$\mathrm{Co}$ & 2.35 \\
$\mathrm{Cr}$ & 1.4 \\
$\mathrm{Mo}$ & 0.5 \\
$\mathrm{Nb}$ & 0.08 \\
$\mathrm{~V}$ & 0.08 \\
$\mathrm{Ti}$ & 0.01 \\
$\mathrm{P}$ & 0.01 \\
$\mathrm{~B}$ & 0.01 \\
$\mathrm{~S}$ & 0.01 \\
$\mathrm{Fe}$ & Balance \\
\hline
\end{tabular}

Nigerian Journal of Technology,
Table 2: The heat treatment conditions of the experimental steel

\begin{tabular}{ll}
\hline Austenisation & $1000^{\circ} \mathrm{C}, 45$ minutes \\
Quenching Medium & Water \\
Tampering & $600^{\circ} \mathrm{C}, 45$ minutes \\
\hline
\end{tabular}

Table 3: The mechanical properties of the experimental steel

\begin{tabular}{|c|c|}
\hline Tensile Strength (MPa) & 1270 \\
\hline Harness (HRC) & 341 \\
\hline Enlongation (\%) & 0.1 \\
\hline Impact toughness $(\mathrm{J})$ & 8.20 \\
\hline
\end{tabular}

\subsection{Ballistic Test}

The ballistic test methodology is explained in detail in the MILSTD-662F [12]. A shot was performed by a $7.62 \mathrm{~mm}$ (calibre) armour piercing projectile with a velocity of $830 \mathrm{~m} / \mathrm{s}$ from $30 \mathrm{~m}$ range. Table 4 shows the shot condition used for the experimental steel.

The $300 \times 1000 \mathrm{~mm}$ steel plate was prepared for the ballistic test which wascarried out at Quality Control (shooting range), Defence Industries Corporation of Nigeria, Nigeria.

The ballistic performance, according to MIL-A-12560 and MIL-A-46100 standards, was reported by Atapeket al. in many studies, as a function of the applied heat treatments $[1,13,14]$.

Table 4: The shot condition for the experimental steel

\begin{tabular}{ll}
\hline Distance & $30 \mathrm{~m}$ \\
Shot angle & $0^{\circ}$ \\
$\begin{array}{l}\text { Projectile type } \\
\text { Ambient temp./ Rel. }\end{array}$ & $7.62-51$ armour piercing \\
humidity & $21^{\circ} \mathrm{C} / 42$ per cent \\
\hline
\end{tabular}

\subsection{Metallographic and Fractographic Examinations}

Samples taken from the experimental steels before and after the shots (from the perforated zones) were prepared by metallographical methods. All samples were prepared by grinding with 320, 600 and 1000 mesh size $\mathrm{Si}$ Ca brasives respectively. Then, the ground surface was polished with $3 \mu \mathrm{m}$ diamond solution. Etching was carried out with nital $(3 \%$ of $\left.\mathrm{HNO}_{3}\right)$ to characterize the microstructure. PhenomProXScanning Electron Microscope (at Ahmadu Bello University, Zaria, Nigeria) was used for both metallographic and fractographic examinations.

\section{RESULTS AND DISCUSSION}

3.1. Microstructure of the quenched/tempered steel plate sample

Generally, the microstructure of steel determines its physical and chemical properties under loading

Vol. 34, No. 2, April 2015 
condition. For armour steel, the matrix having martensitic/bainitict empered martensitic-bainitic structure determines the ballistic performance. This is achieved after application of austenisation and then quenching on low carbon and alloyed steel $[5,15]$. Several studies emphasized that a martensitic/bainitic structure and morphology of these phases, content of retained austenite, austenization/tempering conditions directly affected the final failure mode or ballistic performance of heat treated steels used as armour [16-19]. On the other hand, selection of appropriate material and processing conditions and resulting microstructural and mechanical properties immensely affect the protective characteristics of the material under any dynamic loading.

Figure 1 shows the scanning electron microscope image of the etched experimental steel. The matrix typically exhibits a tempered bainite microstructure. The regions in gray contrast denote the ferritic matrix which refers to decomposed and coarsened lath due to tempering. Intensive precipitates having higher hardness compared to the matrix are seen in dark contrast, since they have lower reflective index. The grain boundaries are clearly seen in the microstructures. As it is well-known, all transformations start at these regions and the austenite grain size must be controlled for higher mechanical requirements [20].

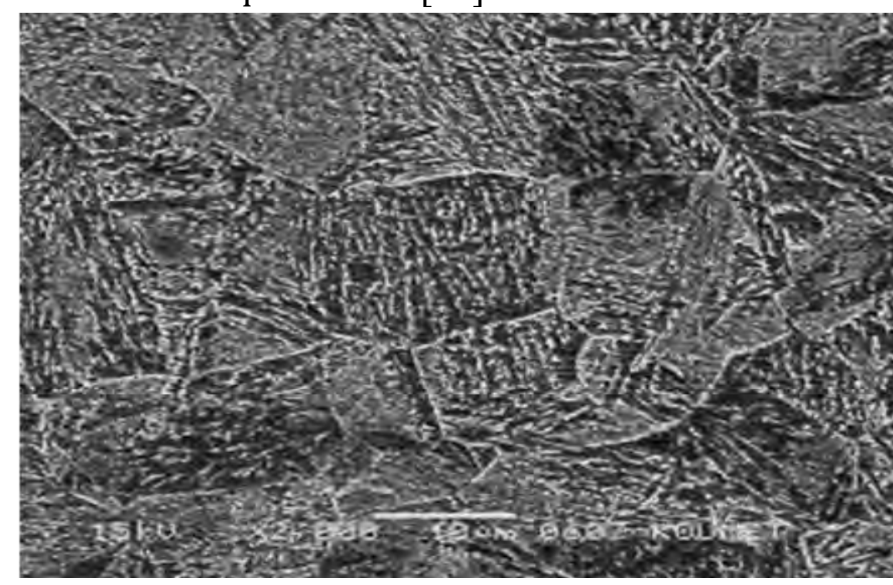

Figure 1: Scanning electron microscope image of the tempered bainite microstructure

\subsection{Macro and micro examinations on the projectile- perforated steel sample}

After the ballistic shot, the cross-section of perforated zone is shown in Figure 2. At the entrance of the steel sheet, a crater (with a certain depth and length) forms at the beginning of the penetration. It is inevitable that the armour steel fails in cleavage fracture, which means no plastic deformation, in the case of the first interaction with a projectile havinghigh strike velocity and kinetic energy. At high strain rates (e.g., some metal cutting operations, projectile impacts with high rates of $100-3600 \mathrm{~m} / \mathrm{s}$ or fracture due to blast), materials exhibit local deformation known as adibatic shear [21, 22]. Adiabatic shear bands (ASBs) are formed as a result of a thermomechanical instability due to the presence of a local inhomogeneity, including local deformation and heating. If the thermal conductivity of the material is not sufficient to conduct the generated heat away, deformation becomes unstable and is localised on surfaces of very small thickness ( $\sim 10 \mu \mathrm{m}$ to $50 \mu \mathrm{m})$.

This situation is compatible in the interaction of a projectile on a steel target. High temperatures can form because of high friction of the projectile during penetration. On microscopic examination, adiabatic shear bands appear as narrow bands in which cracks canpropagate, indicating catastrophic failure of the material [23].

A fractographic analysis was done on perforated steel to determine the crater regions and output line. All examinations are given in Figures3 and 4. The perforated steel was examined in two folds: In the first stage of the examination, it is observed that crater regions have bright and smooth faces indicating no plastic deformation (Figure 3). In the interaction of a projectile with the material, kinetic energy is consumed as fracture, deformation and heat energy in general. For a given armour material, blunting of a sharp projectile causes a decrease in the efficiency of ammunition. Therefore, a requirement for the ballistic performance can be provided. Consuming of energy as fracture plays an important role at this stage. A typical adiabatic shear band formed in the matrix of the experimental steel due to high strain by impact loading of the projectile. Formed adiabatic shear bands play a role on the nucleation and subsequently on the propagation of the crack $[1,2]$.

In the second stage of the examination, it is observed that the steel has a plasticde formation capability under ballistic impact due to yielding in the output line of projectile. In this stage, the perforation mode of the steel is typical petalling (Figure 4).

The formation of deformed and transformed ASBs in the experimental steel after shot has a similarity to the study on AISI 4340 steel, commonly used in dynamic loading test such as high strain rate test, by Bassim, et al [23]. On the other hand, adiabatic shear band results in several perforation modes in armour steel (e.g., plugging and discing type fracture). 


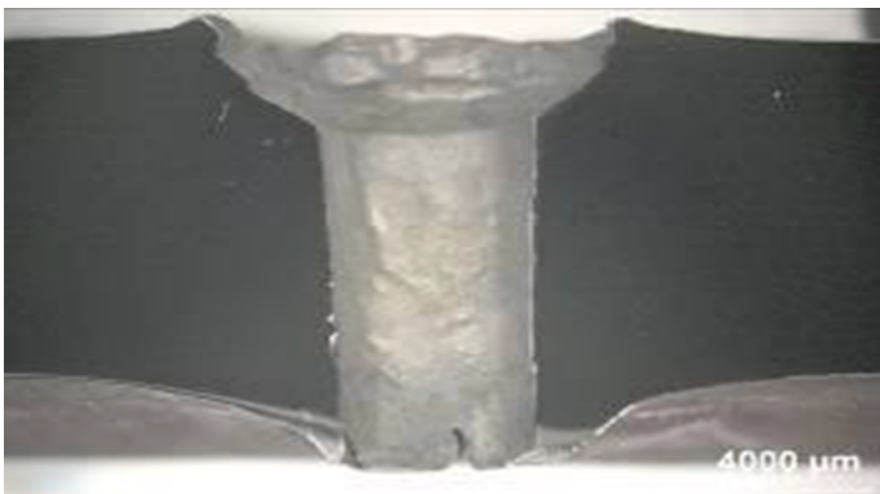

Figure 2: Cross-section of the projectile-perforated steel sample (projectile entrance was from top and left through the lower end of the picture)

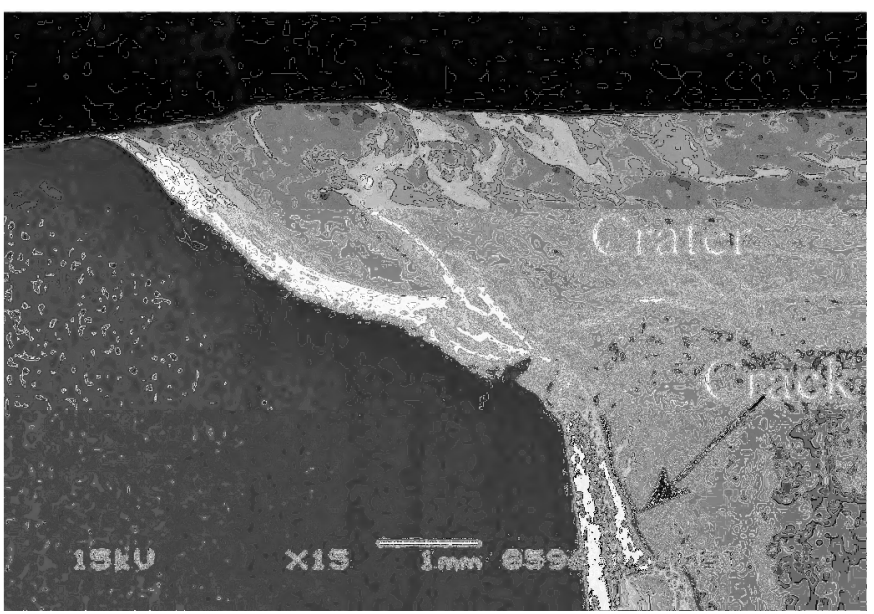

Figure 3: Formation of crater (perforation at entrance) due to penetration of the projectile and the formation of crack because of ASBs followed by the regions of cleavage fracture and abrasive wear

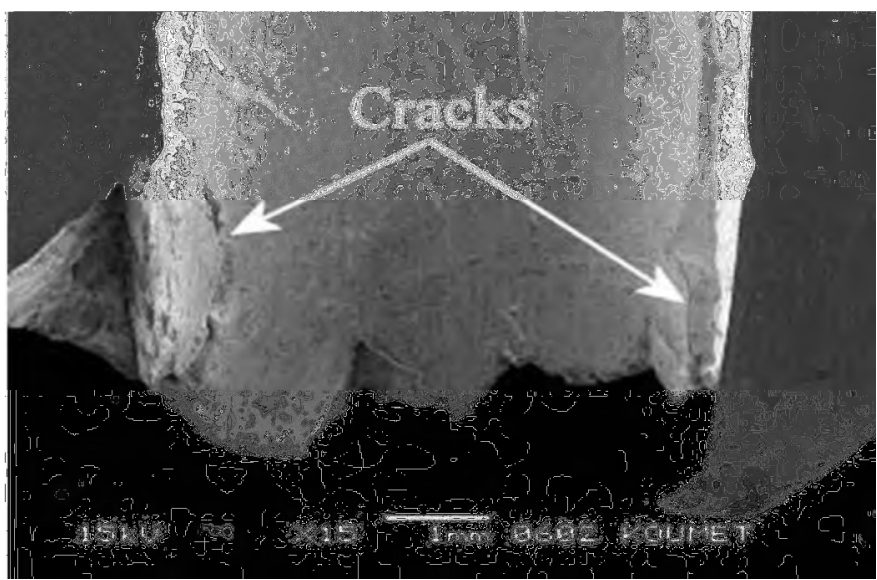

Figure 4:The formation of cracks and petalling at the line of departure (failure formed in the steel after perforation)

\section{CONCLUSIONS}

In this study, the ballistic behaviour of quenched and tempered steel has been investigated. After applied heat treatments consisting of austenisation, quenching and finally tempering, a matrix with 34HRC hardness was obtained. The changes in the microstructure, the deformation and perforation mode of the steel were considered after the shot performed at zero degree with a projectile velocity of $830 \mathrm{~m} / \mathrm{s}$. The experimental steel has a tempered bainitic matrixdue to applied heat treatments stated in Table 2 .

Thematrix exhibits the decomposition of the bainite, which is transformed from austenite grain boundaries by quenching, after tempering. The original matrix was deformed due to over impact loading by the penetration of the projectile. The adiabatic shear bands and cracks near the direction of penetration were observed. The adibatic shear bands were formed as a result of the local heterogeneities, deformation and thermomechanical instability due to overheating bythe friction of projectile moving along the steel. The narrow bands were characterised as white bands after metallographical examinations and the cracks were formed on or close tothe bands. This results in a failure as perforation or fragmentation in the steel.

The fractographical examinations on the cross-section of perforated zone after shot support the microstructural characterisation and the formation in the micro-level (e.g. ,the deformation, the formation of adiabatic shear bands, and cracks). The cleavage type fracture due to strain hardened microstructure close to penetration direction was observed. The formation of the abrasive wear is inevitable under loading and motion of the projectile. The cracks dueto adibatic shear bands were determined both at the first step of the projectile interaction with the steel and also at the line of departure. There is certain elongation from target material to outside at the line of departure and this elongation displays the intensive plastic deformation. The perforation is a typical pedalling, that is breakings from target material/steel.

\section{REFERENCES}

1. Atapek, S. H. "Ballistic Impact Behaviour of Quenched and Tempered Steels" International Iron \& Steel Symposium, April 02-04,2012, Karabük, Turkey, pp.413-419.

2. Atapek, S. H. and Karagoz, S. "Ballistic Impact Behaviour of a Tempered Bainitic Steel Against $7.62 \mathrm{~mm}$ Armour Piercing Projectile", Defence Science Journal, Vol. 61, No. 1, January 2011, pp. 81-87

3. Dwight D. Showalter et al. 'Development and Ballastic Testing of a New Class of High Hardnes Armor Steel" AMMTIAC Quarterly, Volume 4, Number 4, pp. 3-6. 
4. Dwight D. Showalter et al. "Ballistic Testing of Australian Bisalloy Steel for Armor Applications", TheProceedings of the 23rd International Ballistics Symposium, Tarragona, Spain, 16 April 2007, pp. 1-10.

5. Sangoy, L., Meunier, Y. and Pont, G., "Steels for ballistic protection", Israel Journal of Technology, 24, 1988, pp. 319-326.

6. Craig, B. D., Lane, R. A. and Babcock, W. G., "Materials for blast and penetration resistance", AMPTIAC Quartely, 6, 2004, pp. 39-45.

7. Karagöz, Ş., Atapek, Ş. H. and Yılmaz, A., "Microstructural and fractographical studies on quenched and tempered armor steel', Materials Testing, 52(5), 2010, pp. 316-322.

8. US Military Specification MIL-A-46100D(MR)Armour Plate, Steel, Wrought, High-Hardness, USA, 1988

9. US Military Specification MIL-A-46100E(MR)Armour Plate, Steel, Wrought, High-Hardness, USA, 2008 Plate, Steel, Wrought, Homogenous (for Use in Combat-Vehicles and for Ammunition Testing), USA, 1990.

10. XH 129, Thyssen Stahl AG, Specification, Germany.

11. Mars 190, Mars 240, Mars 270, Creusot-Loire, Specification, France.

12. "V50 Ballistic Test for Armor," Department of Defense Test Standard, MIL-STD-662F, December 1997.

13. Atapek, Ş. H. and Karagöz, Ş., "Ballistic impact performance of boron added armor steels", XVII. International Symposium on Boron, Borides and Related Materials, Abstract Book, 143, Istanbul, September 11-17, 2011.

14. Atapek, S. H., "Metallographic and fractographic examinations on a boron added armor steel for characterization of the perforation mode", II. International Conference of Engineering Against Fracture, Session 12.2, Mykonos-Greece, June 2224, 2011.

15. Hu, C. J., Lee, P. Y. and Chen, J. S., "Ballistic performance and microstructure of modified rolled homogeneous armor steel", Journal of the Chinese Institute of Engineers, 25(1), 2002, pp. 99-107.

16. Maweja, K. and Stumpf, W., "The design of advanced performance high strength low-carbon martensitic armour steels: microstructural considerations", Materials Science Engineering A, 480(1-2), 2008, pp. 160-166.

17. Jena, P. K., Kumar, K. S., Krishna, V. R., Singh A. K. and Bhat T. B., "Studies on the role of microstructure on performance of a high strength armour steel', Engineering Failure Analysis, 15(8), 2008, pp. 1088-1096.

18. Jena, P. K., Mishra, B., RameshBabu, M., Babu, A., Singh, A. K., SivaKumar, K. and Bhat, T. B., "Effect of heat treatment on mechanical and ballistic properties of a high strength armour steel", International Journal of Impact Engineering, 37 (3), 2010, pp. 242-249.

19. Maweja, K., Stumpf, W. and Van der Berg, N., "Characteristic of martensite as a function of the $\mathrm{M}_{\mathrm{s}}$-temperature in low-carbon armour steel plates", Material Science Engineering Assembly, 519, 2009, pp. 121-127.

20. Totten, G. E. Steel heat treatment handbook. Second Edition, CRC Press, Boca Raton, 2007.

21. Mills, K., Davis, J. R. and Destefani, J.D. Fractography ASM Handbook, 12, Materials Park, Ohio/USA, 1987.

22. Beckman, E. \& Finnegan, S.A. Metallurgical effects at high strain rates, Plenum Press, USA, 1973.

23. Bassim, M. N. and Odeshi, A.G. "Shear strain localisation and fracture in high strength structural materials",Archives of Material Science Engineering, 2008, 31(2), pp. 69-74.

24. Edwards, M. R. and Mathewson, A. "The ballistic propertiesof tool steel as a potential improvised armour plate", International Journal of Impact Engineering, 1997, 19(4), pp. 297-09.

25. Demir, T., Übeyli, M. and Yildirim, R.O. "Investigation on the ballistic impact behaviour of various alloys against7.62 $\mathrm{mm}$ armour piercing projectile", Materials and Design,2008, 29(10), pp. 2009-2016.

26. Gonçalves, D.P.,De Melo, F.C.L., Klein, A.N. and AlQureshi, H.A. "Analysis and investigation of ballisticimpact on ceramic/metal composite armour", International Journal of Machine Tools Manufacture, 2004, 44(2-3), pp. 307-16.

27. Shokrieh, M.M. and Javadpour, G.H. "Penetration analysisof a projectile in ceramic Composite armour", Composite Structures, 2008, 82(2), pp. 269-276. 